Article

\title{
Bariatric Procedures in Older Adults in the United States: Analysis of a Multicenter Database
}

\author{
Priya Mendiratta ${ }^{1, *, \dagger}$, Neeraj Dayama ${ }^{2,{ }^{\dagger}}$, Gohar Azhar ${ }^{1}$, Pallavi Prodhan ${ }^{1}$ and Jeanne Y. Wei ${ }^{1}$ \\ 1 Department of Geriatrics, Reynolds Institute on Aging, College of Medicine, Department of Geriatrics \\ University of Arkansas Medical Sciences 4301 W. Markham Street, Little Rock, AR 72205, USA; \\ AzharGohar@uams.edu (G.A.); pprodhan7@gmail.com (P.P.); WeiJeanne@uams.edu (J.Y.W.) \\ 2 Department of Health Policy and Management, College of Public Health-University of Arkansas Medical \\ Sciences, Little Rock, AR 72205, USA; NNdayama@uams.edu \\ * Correspondence: pmendiratta@uams.edu; Tel.: +1-(501)-686-6219; Fax: +1-(501)-526-7447 \\ + These authors contributed equally to this work.
}

Received: 25 February 2019; Accepted: 11 April 2019; Published: 21 April 2019

check for updates

\begin{abstract}
Background: Bariatric procedures help reduce obesity-related comorbidities and thus improve survival. Clinical characteristics and outcomes after bariatric procedures in older adults were investigated. Methods: A multi-institutional Nationwide Inpatient Sample (NIS) database was queried from years 2005 through 2012. Older adults $>60$ years of age with procedure codes for bariatric procedures and a diagnosis of obesity/morbid obesity were selected to compare clinical characteristics/outcomes between those undergoing closed versus open procedures and identify risk factors associated with in-hospital mortality and increased hospital length of stay (LOS). Results: Over the study period, 79,122 bariatric procedures were performed. Those undergoing open procedures compared to closed procedures had a higher in-hospital mortality ( $0.8 \%$ vs. $0.2 \%)$ and a longer hospital LOS (4.8 days vs. 2.2 days). Risk factors significantly associated with in-hospital mortality were open procedures, the Western region, and the Elixhauser comorbidity index. Risk factors associated with increased LOS were Medicaid insurance type, an open procedure, a higher Elixhauser comorbidity score, a required skilled nursing facility (SNF) discharge, and died in hospital. Conclusion: Closed bariatric procedures are increasingly being preferred in older adults, with a four-fold lower mortality compared to open procedures. Besides choice of procedure, the presence of specific comorbidities is associated with increased mortality in older adults.
\end{abstract}

Keywords: older adults; bariatric procedures; outcomes

\section{Introduction}

Over the past 25 years, there has been an exponential rise in the prevalence of obesity in the United States. Currently, about $41 \%$ of older adults above 60 years of age are considered obese [1]. Bariatric procedures are recommended for adults with morbid obesity (Class 3 obesity) or in those with a body mass index (BMI) $\geq 35 \mathrm{~kg} / \mathrm{m}^{2}$ (Class 2 obesity) in the presence of high-risk comorbid conditions [2]. With longer life expectancy, coupled with the increased prevalence of obesity and a concomitant decrease in procedure-related risks of complications, greater numbers of older patients are seeking bariatric procedures [3,4]. For these patients, bariatric procedures help reduce many obesity-related comorbidities and thus improve overall survival.

Although a large body of literature informs bariatric procedure utilization in younger adults, the clinical characteristics, temporal case volume trends, and outcomes of bariatric procedures in older adults ( $>60$ years) is still limited [5-10] to single-center reports with smaller sample sizes. Furthermore, older age is itself associated with age-related comorbidities that could potentially augment the risk 
profile of bariatric procedures in older adults. Therefore, in this study, we investigated clinical characteristics, temporal trends in case volume, and outcomes after bariatric surgery in older adults ( $\geq 60$ years of age).

\section{Methods}

\subsection{Data and Sample}

Retrospective data were pooled from the 2005 to 2012 Nationwide Inpatient Sample (NIS) database, which is sponsored by the Agency for Healthcare Research and Quality as part of the Healthcare Cost and Utilization Project (HCUP). The NIS database is the largest publicly available all-payer inpatient care database in the United States, representing a $20 \%$ stratified sample of all U.S. community hospitals. The HCUP was used to create national estimates for trends analyses [11,12].

All patients aged 60 years or older with an "International Classification of Disease, 9th Revision, Clinical Modification" procedure code of laparoscopic gastric bypass (44.38), open gastric bypass (44.31 and 44.39), laparoscopic gastric band (44.95), and laparoscopic gastroplasty (44.68) with principal diagnosis codes of obesity and morbid obesity $(278.0,278.01,278.8$, and 278.1) were selected. Patients transferred to another short-term hospital were excluded to avoid double counting. Approval for use of the NIS patient-level data in this study was obtained from the Institutional Review Board of the University of Arkansas for Medical Sciences.

\subsection{Study Variables}

The data variables investigated were categorized as patient-specific factors (age, gender, race, payer type), obesity-specific factors (comorbidities), and procedure-specific factors (operative technique (laparoscopic versus open type) and outcome variables). The outcome measures investigated were in-hospital mortality and hospital length of stay after undergoing a bariatric procedure. The study hypotheses were that (a) older age, (b) specific racial groups, and (c) the presence of chronic medical conditions were not associated with increased mortality after a bariatric procedure.

\subsection{Data Analyses}

Patient and hospital characteristics are presented as relative frequencies and percentages for each independent variable. All values for continuous variables are expressed as means \pm standard deviations. $T$-statistics were calculated to analyze the overall trend of each independent variable during the study period. Univariate and multivariate regression analyses were performed to identify independent predictors of in-hospital mortality and hospital length of stay. A generalized linear model with a logit link and gamma distribution was fitted for right-skewed cost data as a function of all independent variables. [7] Statistical evaluations were performed using SAS version 9.2 (SAS Institute, Cary, NC, USA), and statistical significance was defined as $p<0.05$.

\section{Results}

Over the study period, 79,122 bariatric procedures were performed. The majority of the procedures were closed procedures $(92.2 \%)$. Figure 1 shows the statistically significant temporal trends of bariatric procedures over the study period. The numbers of open and closed procedures peaked in 2008 and 2009, respectively.

Table 1 shows the clinical characteristics of the study population and compares subjects undergoing closed versus open procedures. Subjects undergoing open procedures compared to those undergoing closed procedures were more likely to have the following characteristics: Older age (63.3 years vs. 42.2 years), female gender ( $73.7 \%$ vs. $70.6 \%)$, care from rural hospitals ( $7 \%$ vs. $3.8 \%)$, Medicaid $(2.8 \%$ vs. $1.5 \%$ ), private insurance ( $48.6 \%$ vs. $42.7 \%$ ), a higher mean Elixhauser comorbidity index (2.5 vs. 2.4$)$, chronic liver disease (13.8\% vs. 9.8\%), a longer hospital length of stay (LOS) (4.8 days vs. 2.2 days), a required SNF discharge ( $4.9 \%$ vs. $0.8 \%)$, and higher in-hospital mortality ( $0.8 \%$ vs. $0.2 \%)$. In contrast, 
those undergoing closed procedures compared to those undergoing open procedures were more likely to have the following characteristics: Care from an urban nonteaching hospital (44.3\% vs. 35.4\%), care in the Western region ( $25.7 \%$ vs. $15.7 \%$ ), Medicare (48.2\% vs. $40 \%$ ), hyperlipidemia (57.2\% vs. $50.2 \%)$, hypertension $(77.7 \%$ vs. $73.9 \%)$, and a routine discharge ( $95.4 \%$ vs. $85 \%$ ).

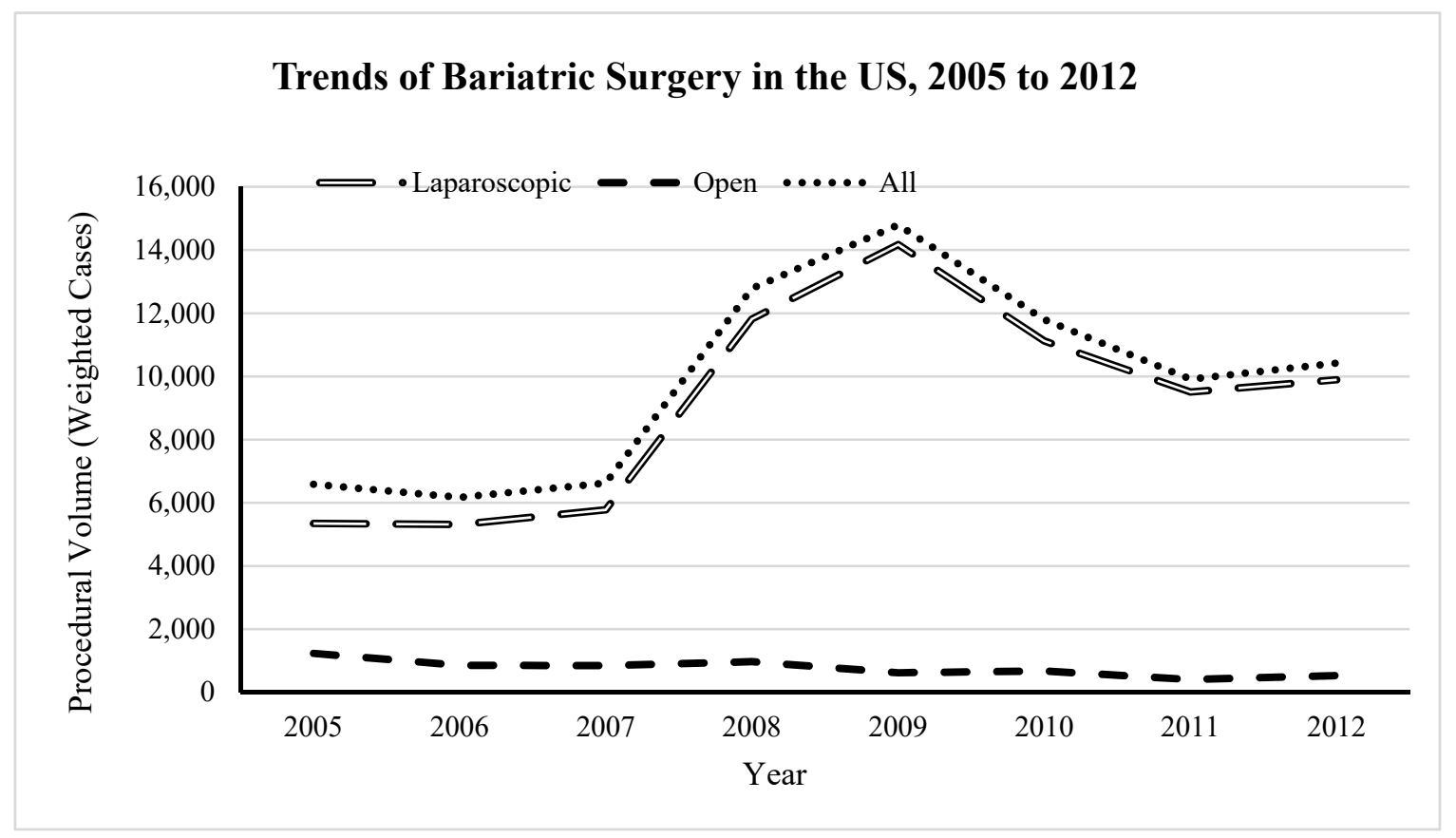

Figure 1. Temporal trends of bariatric procedures in the United States in older adults, 2005-2012.

Table 1. Comparison of clinical characteristics between patients undergoing open versus closed bariatric procedures. LOS: Length of stay.

\begin{tabular}{ccccc}
\hline Characteristic & $\begin{array}{c}\text { Total } \\
n=79,122\end{array}$ & $\begin{array}{c}\text { Laparoscopic } \\
n=72,696\end{array}$ & $\begin{array}{c}\text { Open } \\
n=6153\end{array}$ & $p$-Value \\
\hline Demographics & & & & \\
Age & $64.16(7.7)$ & $64.23(7.8)$ & $63.29(6.6)$ & $<0.0001$ \\
Age 60 to 70 & 74,556 & $68,560(92)$ & $5997(8)$ & 0.0002 \\
Age 71 to 80 & 4565 & $4409(96.6)$ & $157(3.4)$ & 0.0002 \\
Female gender & 56,025 & $51,493(92)$ & $4532(8)$ & 0.0315 \\
Race & & & & \\
White & 57,970 & $53,673(92.6)$ & $4297(7.4)$ & 0.4639 \\
Black & 4592 & $4212(91.7)$ & $379(8.3)$ & 0.3426 \\
Hispanic & 3110 & $2942(94.6)$ & $168(5.4)$ & 0.1568 \\
Insurance type & & & & \\
Private & 34,150 & $31,169(91.3)$ & $2981(8.7)$ & 0.0129 \\
Medicare & 37,611 & $35,152(93.5)$ & $2460(6.5)$ & 0.0004 \\
Medicaid & 1239 & $1069(86.3)$ & $170(13.7)$ & 0.0022 \\
Hospital type & & & & \\
Rural & 3207 & $2777(86.6)$ & $429(13.4)$ & 0.0173 \\
Urban Nonteaching & 34,468 & $32,287(93.7)$ & $2180(6.3)$ & 0.0474 \\
Urban teaching & 40,929 & $37,413(91.4)$ & $3516(8.6)$ & 0.181 \\
Hospital location & & & & \\
Northeast & 16,306 & $14,667(89.9)$ & $1639(10.1)$ & 0.0772 \\
Midwest & 17,688 & $16,170(91.4)$ & $1518(8.6)$ & 0.4552 \\
South & 25,386 & $23,355(92)$ & $2031(8)$ & 0.8165 \\
West & 19,742 & $18,777(95.1)$ & $965(4.9)$ & 0.001 \\
\hline
\end{tabular}


Table 1. Cont.

\begin{tabular}{ccccc}
\hline Characteristic & $\begin{array}{c}\text { Total } \\
n=\mathbf{7 9 , 1 2 2}\end{array}$ & $\begin{array}{c}\text { Laparoscopic } \\
\boldsymbol{n}=\mathbf{7 2 , 6 9 6}\end{array}$ & $\begin{array}{c}\text { Open } \\
n=\mathbf{6 1 5 3}\end{array}$ & $p$-Value \\
\hline Comorbidities & & & & \\
Elixhauser comorbidity index & $2.39(2.8)$ & $2.38(2.8)$ & $2.5(3.1)$ & $<0.0001$ \\
CHF (Congestive heart failure) & 2831 & $2583(91.2)$ & $248(8.8)$ & 0.466 \\
Hypertension & 61,225 & $56,677(92.6)$ & $4547(7.4)$ & 0.0025 \\
COPD (Chronic obstructive & 16,596 & $15,270(92)$ & $1326(8)$ & 0.6533 \\
pulmonary disease) & 40,327 & $37,248(92.4)$ & $3079(7.6)$ & 0.49 \\
Diabetes & 1223 & $1112(91)$ & $111(9)$ & 0.4474 \\
Peripheral vascular disease & 3141 & $2874(91.5)$ & $268(8.5)$ & 0.4679 \\
Renal failure & 7972 & $7121(89.3)$ & $851(10.7)$ & 0.0221 \\
Chronic liver disease & 13,097 & $11,971(91.4)$ & $1126(8.6)$ & 0.1771 \\
Apnea & 44,839 & $41,749(93.1)$ & $3091(6.9)$ & $<0.0001$ \\
Hyperlipidemia & 1333 & $1230(92.3)$ & $103(7.7)$ & 0.9856 \\
Smoking & & & & \\
Outcomes & 189 & $140(73.7)$ & $50(26.3)$ & $<0.0001$ \\
Died & $2.39(8.52)$ & $2.16(7.1)$ & $4.80(18.3)$ & $<0.0001$ \\
LOS mean (Length of stay) & 74,801 & $69,573(93)$ & $5229(69.9)$ & $<0.0001$ \\
Routine discharge & 878 & $577(65.7)$ & $301(34.3)$ & $<0.0001$ \\
SNF (Skilled nursing facility) & & &
\end{tabular}

\subsection{Risk Factors Analysis}

Nonsurvivors, when compared to survivors (Table 2), were more likely to have the following characteristics: Having undergone an open procedure (26.3\% vs. $7.7 \%)$, an older mean age (65.1 years vs. 64.1 years), a higher mean Elixhauser index (3.2 vs. 2.9$)$, congestive heart failure $(9.4 \%$ vs. $3.6 \%)$, COPD (33.1\% vs. $21 \%)$, peripheral artery disease ( $10.2 \%$ vs. $1.5 \%)$, and a higher mean hospital LOS ( 25.9 d vs. 2.3 d). Risk factors significantly associated with in-hospital mortality (multivariable analysis, Table 3) for subjects undergoing a bariatric procedure were open procedures (odds ratio (OR) 4.1;95\% confidence interval (CI) 1.8-9.1), the Western region (OR 3.3, 95\% CI 1.04-10.3), and an Elixhauser comorbidity index (OR 1.5, 95\% CI 1.1-2.02).

Table 2. Comparison of survivors and nonsurvivors among patients undergoing bariatric procedures.

\begin{tabular}{ccccc}
\hline Variables & Total & Alive & Dead & $p$-Value \\
& $\mathbf{7 9 , 1 2 2}$ & $n=\mathbf{7 8 , 9 3 2}$ & $\mathbf{n = 1 8 9}$ & \\
\hline Age & $64.16(7.1)$ & $64.15(7.7)$ & $65.14(6.9)$ & $<0.0001$ \\
Age 60 to 70 & 74,556 & $74,380(99.8)$ & $176(0.2)$ & 0.7371 \\
Age $>$ 71 & 4565 & $4552(99.8)$ & $13(0.2)$ & 0.7371 \\
Female gender & 56,025 & $55,891(99.8)$ & $134(0.2)$ & 0.997 \\
Race & & & & \\
White & 57,970 & $57,845(99.8)$ & $125(0.2)$ & 0.3076 \\
Black & 4592 & $4573(99.5)$ & $18(0.5)$ & 0.2703 \\
Hispanic & 3110 & $3094(99.5)$ & $15(0.5)$ & 0.1783 \\
Insurance type & & & & \\
Private & 34,150 & $34,089(99.8)$ & $61(0.2)$ & 0.1492 \\
Medicare & 37,611 & $37,498(99.7)$ & $114(0.3)$ & 0.1 \\
Medicaid & 1239 & $1234(99.6)$ & $5(0.5)$ & 0.6671 \\
Hospital type & & & & \\
Rural & 3207 & $3203(99.9)$ & $4(0.1)$ & 0.4298 \\
Urban nonteaching & 34,468 & $34,394(99.8)$ & $74(0.2)$ & 0.5688 \\
Urban teaching & 40,929 & $40,818(99.7)$ & $111(0.3)$ & 0.3593 \\
\hline
\end{tabular}


Table 2. Cont.

\begin{tabular}{|c|c|c|c|c|}
\hline Variables & $\begin{array}{c}\text { Total } \\
79,122\end{array}$ & $\begin{array}{c}\text { Alive } \\
n=78,932\end{array}$ & $\begin{array}{c}\text { Dead } \\
n=189\end{array}$ & $p$-Value \\
\hline \multicolumn{5}{|l|}{ Hospital location } \\
\hline North East & 16,306 & $16,284(99.9)$ & $22(0.1)$ & 0.1427 \\
\hline M West & 17,688 & $17,644(99.8)$ & $44(0.2)$ & 0.9143 \\
\hline South & 25,386 & $25,310(99.7)$ & $76(0.3)$ & 0.288 \\
\hline West & 19,742 & $19,694(99.8)$ & $48(0.2)$ & 0.959 \\
\hline \multicolumn{5}{|l|}{ Type of procedure } \\
\hline Laparoscopic/closed & 72,969 & $72,829(99.8)$ & $140(0.2)$ & $<0.0001$ \\
\hline $\begin{array}{l}\text { Open procedure } \\
\text { Comorbidity }\end{array}$ & 6153 & $6103(99.1)$ & $50(0.9)$ & $<0.0001$ \\
\hline Elixhauser comorbidity index & $2.39(2.8)$ & $2.9(2.8)$ & $3.2(3.8)$ & $<0.0001$ \\
\hline $\mathrm{CHF}$ & 2831 & $2813(99.3)$ & $18(0.7)$ & 0.0381 \\
\hline Hypertension & 61,225 & $61,146(99.9)$ & $79(0.1)$ & $<0.0001$ \\
\hline COPD & 16,596 & $16,533(99.6)$ & $63(0.4)$ & 0.0423 \\
\hline Apnea & 13,097 & $13,083(99.8)$ & $14(0.2)$ & 0.1282 \\
\hline Smoking & 1333 & $1325(99.4)$ & $8(0.6)$ & 0.1954 \\
\hline Renal failure & 3141 & 3114 (99.1) & $27(0.9)$ & 0.0006 \\
\hline Chronic liver disease & 7972 & 7949 (99.7) & $23(0.3)$ & 0.7113 \\
\hline Diabetes & 40,327 & $40,247(99.8)$ & $80(0.2)$ & 0.3117 \\
\hline Peripheral vascular disease & 1223 & $1204(98.5)$ & $19(1.5)$ & $<0.0001$ \\
\hline Hyperlipidemia & 44,839 & $44,784(99.9)$ & $55(0.1)$ & 0.0007 \\
\hline Length of stay & $2.36(8.7)$ & $2.31(6.3)$ & $25.88(109.2)$ & $<0.0001$ \\
\hline
\end{tabular}

Table 3. Risk factor analysis for in-hospital mortality among patients undergoing bariatric procedures.

\begin{tabular}{|c|c|c|c|c|c|c|c|c|}
\hline \multirow{2}{*}{ Variables } & \multicolumn{4}{|c|}{ Univariate } & \multicolumn{4}{|c|}{ Multivariate } \\
\hline & \multirow[t]{2}{*}{ OR } & \multicolumn{2}{|c|}{$95 \%$ CI } & \multirow{3}{*}{$\begin{array}{c}p \text {-Value } \\
0.74\end{array}$} & \multirow{2}{*}{ OR } & \multicolumn{2}{|c|}{$95 \%$ CI } & \multirow[t]{2}{*}{$p$-Value } \\
\hline & & & & & & & & \\
\hline Age 60 to 70 & 0.82 & 0.26 & 2.6 & & Reference & & & \\
\hline Age $>71$ & 1.22 & 0.38 & 3.85 & 0.74 & 1.00 & 0.26 & 3.93 & 1.00 \\
\hline $\begin{array}{l}\text { Female gender } \\
\text { Race }\end{array}$ & 1.00 & 0.51 & 1.94 & 1.00 & 0.77 & 0.36 & 1.64 & 0.50 \\
\hline White & 0.65 & 0.28 & 1.5 & 0.31 & Reference & & & \\
\hline Black & 1.8 & 0.62 & 5.17 & 0.28 & 2.05 & 0.68 & 6.21 & 0.21 \\
\hline Hispanic & 2.21 & 0.67 & 7.23 & 0.19 & 2.63 & 0.81 & 8.58 & 0.11 \\
\hline Insurance type & & & & & & & & \\
\hline Private & 0.62 & 0.33 & 1.19 & 0.15 & Reference & & & \\
\hline Medicare & 1.67 & 0.9 & 3.12 & 0.11 & 1.34 & 0.65 & 2.76 & 0.43 \\
\hline Medicaid & 1.54 & 0.21 & 11.32 & 0.67 & 1.39 & 0.17 & 11.6 & 0.76 \\
\hline Hospital type & & & & & & & & \\
\hline Rural & 0.47 & 0.07 & 3.19 & 0.44 & Reference & & & \\
\hline Urban nonteaching & 0.83 & 0.44 & 1.56 & 0.57 & 1.11 & 0.14 & 8.99 & 0.92 \\
\hline Urban teaching & 1.34 & 0.72 & 2.5 & 0.36 & 1.37 & 0.16 & 11.74 & 0.78 \\
\hline Hospital location & & & & & & & & \\
\hline North East & 0.5 & 0.2 & 1.29 & 0.15 & Reference & & & \\
\hline Mid West & 1.04 & 0.52 & 2.09 & 0.91 & 2.68 & 0.75 & 9.66 & 0.13 \\
\hline South & 1.42 & 0.74 & 2.72 & 0.29 & 2.45 & 0.77 & 7.75 & 0.13 \\
\hline West & 1.02 & 0.48 & 2.16 & 0.96 & 3.23 & 1.02 & 10.15 & 0.05 \\
\hline Type of procedure & & & & & & & & \\
\hline Laparoscopic/closed & & & & & Reference & & & \\
\hline $\begin{array}{l}\text { Open procedure } \\
\text { Comorbidity }\end{array}$ & 4.25 & 2.11 & 8.56 & 0.00 & 4.03 & 1.81 & 8.95 & 0.00 \\
\hline Elixhauser comorbidity index & 1.52 & 1.19 & 1.94 & 0.00 & 1.76 & 1.29 & 2.42 & 0.00 \\
\hline $\mathrm{CHF}$ & 2.81 & 1.01 & 7.84 & 0.05 & 0.82 & 0.19 & 3.61 & 0.79 \\
\hline
\end{tabular}


Table 3. Cont

\begin{tabular}{ccccccccc}
\hline \multirow{2}{*}{ Variables } & \multicolumn{4}{c}{ Univariate } & \multicolumn{4}{c}{ Multivariate } \\
\cline { 2 - 9 } & OR & $\mathbf{9 5 \%} \mathbf{C I}$ & $\boldsymbol{p}$-Value & OR & $\mathbf{9 5 \%} \mathbf{C I}$ & $\boldsymbol{p}$-Value \\
\hline Hypertension & 0.21 & 0.11 & 0.39 & 0.00 & 0.17 & 0.08 & 0.36 & 0.00 \\
COPD & 1.87 & 1.01 & 3.47 & 0.05 & 0.77 & 0.35 & 1.68 & 0.51 \\
Apnea & 0.41 & 0.13 & 1.34 & 0.14 & 0.34 & 0.08 & 1.55 & 0.16 \\
Smoking & 2.52 & 0.59 & 10.7 & 0.21 & 2.91 & 0.63 & 13.56 & 0.17 \\
Renal failure & 4.12 & 1.7 & 9.97 & 0.00 & 0.37 & 0.1 & 1.37 & 0.14 \\
Chronic liver disease & 1.23 & 0.4 & 3.78 & 0.71 & 0.73 & 0.22 & 2.48 & 0.62 \\
Diabetes & 0.71 & 0.37 & 1.38 & 0.31 & 0.66 & 0.31 & 1.39 & 0.27 \\
Peripheral vascular disease & 7.37 & 2.67 & 20.36 & 0.00 & 2.21 & 0.37 & 13.33 & 0.39 \\
Hyperlipidemia & 0.31 & 0.16 & 0.63 & 0.00 & 0.27 & 0.12 & 0.59 & 0.00 \\
\hline
\end{tabular}

\subsection{Hospital Length of Stay}

The risk factors associated with an increased length of stay were Medicaid insurance type (OR 1.13, 95\% CI 1.00-1.27), an open procedure (OR 1.74, 95\% CI 1.62-1.88), a higher Elixhauser comorbidity score (OR 1.10, 95\% CI 1.08-1.12), a required SNF discharge (OR 2.73, 95\% CI 2.17-3.44), and nonsurvivors (OR 4.87, 95\% CI 2.35-10.12) (Supplemental Materials, Table S1).

\section{Discussion}

Our study utilized a large multicenter national database to provide an in-depth analysis of trends and outcomes of bariatric procedures among obese older adults. In this population, our results highlighted (a) the temporal trend in bariatric procedures, (b) a comparison of the clinical characteristics and outcomes between those undergoing closed versus open procedures, and (c) an identification of the unique risk factors associated with in-hospital mortality and increased hospital LOS.

The procedure-related temporal trends indicated that open procedure rates in older adults declined from $18.6 \%$ in 2005 to $5.1 \%$ in 2012 . This trend was similar to that noted in all adult populations, where the frequency of open procedures declined from 14\% [13] in the 2006-2008 era to 2.9\% in 2012 [14]. This indicates an increasing preference for closed procedures, given their efficacy and better outcomes over open procedures. Previous studies have shown that older age is a risk factor for mortality [15-17] after bariatric procedures. In a study of 1067 consecutive patients, Livingston et al. [15] reported that patients 55 years and older had a three-fold greater mortality from gastric bypass surgery compared to younger patients. However, within the older adult population, we found that older age ( $>71$ years), when compared to 60-70 years of age, did not confer any additional mortality risk. Surprisingly, in our study, age $>71$ years was also associated with a shorter hospital LOS compared to those between the ages of 60 and 70 years. Additionally, despite a higher prevalence of obesity in blacks and Hispanics compared to whites [1], we did not find any differences in mortality among these racial groups after bariatric procedures.

We found that the type of bariatric procedure performed (open versus closed) in older adults was an independent risk factor for in-hospital mortality. Closed procedures were associated with a four-fold lower mortality rate $(0.2 \%)$ compared to open procedures $(0.8 \%)$. These rates were similar to those that have been reported previously [18,19]. Nguyen et al. [13] indicated a mortality of $0.06 \%$ and $0.03 \%$ for laparoscopic gastric bypass and gastric banding, respectively, in a cohort of adults of all ages undergoing bariatric procedures between 2006 and 2008. Similarly, to our report, mortality was significantly higher for open procedures $(0.52 \%)$. In a more recent report in adults, the majority of which were patients undergoing (97\%) closed procedures, the in-hospital mortality ranged from $0.10 \%$ in 2010 to $0.07 \%$ in 2012 [14]. These temporal trends in mortality outcomes in recent decades have been an improvement over earlier outcomes: Mortality from closed procedures in 1998 was $0.8 \%$, but it decreased to $0.5 \%$ by 2002 [20]. Similarly, Lancaster et al. [21] analyzed the American College of Surgeons National Surgical Quality Improvement Program (ACS-NSQIP) and similarly reported 
a significantly greater 30-day mortality after open versus laparoscopic gastric bypass (0.79\% vs. $0.17 \%$, respectively). However, in contrast to previous studies, where adult populations of all ages were studied, our investigation uniquely focused on older adults only. The overall improvement in mortality outcomes in older adults are multifactorial and possibly reflect increasing experience with greater case volumes, a broader adoption of the laparoscopic approach, appropriate fellowship training programs, and overall improvement in perioperative care. Surprisingly, in our study, we noted that patients undergoing open procedures had a higher Elixhauser comorbidity index in comparison to those undergoing closed procedures. It is unknown why open procedures were performed in those with more comorbidities. It can only be speculated that physician preference for open procedures over closed procedures may have been dictated in part by their limited training in laparoscopic procedures in earlier eras, and thus there was a propensity for a surgeon to perform open procedures even on those with increased comorbidities. These differences between open and closed procedures were undoubtedly related to the overall invasiveness of the open procedures. Nevertheless, this finding highlights the importance of informed procedural choice for older adults who have decreased physiological reserves and more associated comorbidities. Our report highlights the need to individualize procedural choice on a case-by-case basis, given a higher risk of mortality with open procedures in older adults.

Comorbidity, as indicated by the Elixhauser comorbidity score, was associated with increasing mortality and hospital LOS. However, none of the specific comorbid conditions investigated conferred a higher risk of mortality. These results were similar to those reported by Nguyen et al. [13]. However, in contrast, Carbonell et al. [22] did not find a correlation between comorbidities and greater mortality. In addition, contrary to our findings, Fernandez et al. [23] found hypertension to be predictive of greater perioperative mortality in a multivariate analysis of 2011 patients who underwent open and laparoscopic gastric bypass. When offering bariatric procedures to older adults, it is thus important to risk-stratify patients based on their comorbidities, and the use of well-validated preoperative risk profile scoring systems may further help about the impact of comorbidities among older adults as well [24].

There were limitations to this study. The NIS database is compiled from discharge abstract data and is limited to in-hospital stays without outpatient follow-up data. For example, deaths that occurred after discharge would not have been captured in this database, an underestimate of overall mortality. Many factors, such as other disparities not included in the analysis, the surgical volume of operations, the provider level, and clustering of cases/outcomes within hospitals, which may have affected mortality and are sources of bias in such a study, were not analyzed in this study. Last, we recognize the limitation of the dataset in gleaning reasons on what informed the choice of bariatric procedure in older adults. Information regarding the decisions relating to choose by surgeons and patients/their families was not available in the NIS database. Our dataset included a study period until 2012. It would have been important to include recent data. However, funding issues limited our ability to procure recent data. Despite these limitations, this novel study is the largest to date in evaluating factors predictive of mortality in bariatric surgery, specifically in older adult patients.

\section{Conclusions}

Bariatric surgery is increasingly being offered to older adults with a preference for closed procedures. Open procedures are associated with a four-fold increased mortality compared to closed procedures. Besides choice of procedure (open vs. closed), the presence of specific comorbidities is associated with increased mortality in older adult patients. Our report stresses the need to individualize bariatric surgery choice based on a case-by-case evaluation of the type of procedure offered and the presence of comorbidities.

Supplementary Materials: The following are available online at http://www.mdpi.com/2308-3417/4/2/32/s1, Table S1: Risk factor analysis (univariate and multivariate) for hospital length of stay among patients undergoing a bariatric procedure. 
Author Contributions: Conceptualization, P.M.; methodology, P.M. and N.D.; software, N.D.; validation, P.M.; formal analysis, N.D.; investigation, N.D. and G.A.; resources, J.Y.W.; data curation, N.D. and P.M.; original draft preparation, P.M., P.P. and N.D.; writing-P.M., P.P., N.D.; review and editing, P.M., P.P., N.D., G.A. and J.Y.W.; supervision, P.M.; funding acquisition, P.M. and J.Y.W.

Conflicts of Interest: The authors declare no conflicts of interest.

\section{References}

1. Hales, C.M.; Carroll, M.D.; Fryar, C.D.; Ogden, C.L. Prevalence of Obesity Among Adults and Youth: United States, 2015-2016. NCHS Data Brief 2017, 288, 1-8.

2. Gastrointestinal surgery for severe obesity: National Institutes of Health Consensus Development Conference Statement. Am. J. Clin. Nutr. 1992, 55, 615S-619S. [CrossRef]

3. Colquitt, J.L.; Pickett, K.; Loveman, E.; Frampton, G.K. Surgery for weight loss in adults. Cochrane Database Syst. Rev. 2014, 8, CD003641. [CrossRef] [PubMed]

4. Dorman, R.B.; Abraham, A.A.; Al-Refaie, W.B.; Parsons, H.M.; Ikramuddin, S.; Habermann, E.B. Bariatric surgery outcomes in the elderly: An ACS NSQIP study. J. Gastrointest. Surg. 2012, 16, 35-44. [CrossRef] [PubMed]

5. Moon, R.C.; Kreimer, F.; Teixeira, A.F.; Campos, J.M.; Ferraz, A.; Jawad, M.A. Morbidity rates and weight loss after Roux-en-Y gastric bypass, sleeve gastrectomy, and adjustable gastric banding in patients older than 60 years old: Which procedure to choose? Obes. Surg. 2016, 26, 730-736. [CrossRef] [PubMed]

6. Abbas, M.; Cumella, L.; Zhang, Y.; Choi, J.; Vemulapalli, P.; Melvin, W.S.; Camacho, D. Outcomes of Laparoscopic Sleeve Gastrectomy and Roux-en-Y Gastric Bypass in Patients Older than 60. Obes. Surg. 2015, 25, 2251-2256. [CrossRef]

7. Yoon, J.; Sherman, J.; Argiroff, A.; Chin, E.; Herron, D.; Inabnet, W.; Kini, S.; Nguyen, S. Laparoscopic Sleeve Gastrectomy and Gastric Bypass for The Aging Population. Obes. Surg. 2016, 26, 2611-2615. [CrossRef] [PubMed]

8. Spaniolas, K.; Trus, T.L.; Adrales, G.L.; Quigley, M.T.; Pories, W.J.; Laycock, W.S. Early morbidity and mortality of laparoscopic sleeve gastrectomy and gastric bypass in the elderly: A NSQIP analysis. Surg. Obes. Relat. Dis. 2014, 10, 584-588. [CrossRef]

9. Robert, M.; Pasquer, A.; Espalieu, P.; Laville, M.; Gouillat, C.; Disse, E. Gastric Bypass for Obesity in the Elderly: Is It as Appropriate as for Young and Middle-Aged Populations? Obes. Surg. 2014, 24, 1662-1669. [CrossRef] [PubMed]

10. Soto, F.C.; Gari, V.; De La Garza, J.R.; Szomstein, S.; Rosenthal, R.J. Sleeve Gastrectomy in the Elderly: A Safe and Effective Procedure with Minimal Morbidity and Mortality. Obes. Surg. 2013, 23, 1445-1449. [CrossRef] [PubMed]

11. Rockville, M.D. HCUP National Inpatient Sample (NIS); Healthcare Cost and Utilization Project (HCUP); Agency for Healthcare Research and Quality (AHRQ): Rockville, MD, USA, 2012. Available online: www.hcup-us.ahrq.gov/nisoverview.jsp (accessed on 20 April 2019).

12. Houchens, R.L.; Ross, D.; Elixhauser, A. Using the HCUP national inpatient sample to estimate trends (revised 12/15/15); HCUP methods Series Report \#2006-05; Agency for Healthcare Research and Quality: Rockville, MD, USA, 4 January 2016. Available online: http://Www.hcup-us.ahrq.gov/reports/methods/methods.jsp (accessed on 1 December 2018).

13. Nguyen, N.T.; Masoomi, H.; Laugenour, K.; Sanaiha, Y.; Reavis, K.M.; Mills, S.D.; Stamos, M.J. Predictive factors of mortality in bariatric surgery: Data from the Nationwide Inpatient Sample. Surgery 2011, 150, 347-351. [CrossRef]

14. Nguyen, N.T.; Nguyen, B.; Gebhart, A.; Hohmann, S. Changes in the makeup of bariatric surgery: A national increase in use of laparoscopic sleeve gastrectomy. Surg. Endosc. 2016, 30, 2723-2727. [CrossRef] [PubMed]

15. Livingston, E.H.; Langert, J. The Impact of Age and Medicare Status on Bariatric Surgical Outcomes. Arch. Surg. 2006, 141, 1115-1120. [CrossRef]

16. Papasavas, P.K.; Gagné, D.J.; Kelly, J.; Caushaj, P.F. Laparoscopic Roux-En-Y Gastric Bypass is a Safe and Effective Operation for the Treatment of Morbid Obesity in Patients Older than 55 Years. Obes. Surg. 2004, 14, 1056-1061. [CrossRef] [PubMed] 
17. Flum, D.R.; Salem, L.; Elrod, J.A.B.; Dellinger, E.P.; Cheadle, A.; Chan, L. Early Mortality Among Medicare Beneficiaries Undergoing Bariatric Surgical Procedures. JAMA 2005, 294, 1903-1908. [CrossRef] [PubMed]

18. Hinojosa, M.W.; Varela, J.E.; Parikh, D.; Smith, B.R.; Nguyen, X.-M.; Nguyen, N.T. National trends in use and outcome of laparoscopic adjustable gastric banding. Surg. Obes. Relat. Dis. 2009, 5, 150-155. [CrossRef]

19. Zhang, L.; Scott, J.; Shi, L.; Truong, K.; Hu, Q.; Ewing, J.A.; Chen, L. Changes in utilization and peri-operative outcomes of bariatric surgery in large U.S. hospital database, 2011-2014. PLoS ONE 2017, 12, e0186306. [CrossRef]

20. Nguyen, N.T.; Root, J.; Zainabadi, K.; Sabio, A.; Chalifoux, S.; Stevens, C.M.; Mavandadi, S.; Longoria, M.; Wilson, S.E. Accelerated Growth of Bariatric Surgery with the Introduction of Minimally Invasive Surgery. Arch. Surg. 2005, 140, 1198-1202. [CrossRef]

21. Lancaster, R.T.; Hutter, M.M. Bands and bypasses: 30-day morbidity and mortality of bariatric surgical procedures as assessed by prospective, multi-center, risk-adjusted ACS-NSQIP data. Surg. Endosc. 2008, 22, 2554-2563. [CrossRef]

22. Fernandez, A.Z.; DeMaria, E.J.; Tichansky, D.S.; Kellum, J.M.; Wolfe, L.G.; Meador, J.; Sugerman, H.J. Multivariate Analysis of Risk Factors for Death Following Gastric Bypass for Treatment of Morbid Obesity. Ann. Surg. 2004, 239, 698-703. [CrossRef]

23. Carbonell, A.M.; Lincourt, A.E.; Matthews, B.D.; Kercher, K.W.; Sing, R.F.; Heniford, B.T. National study of the effect of patient and hospital characteristics on bariatric surgery outcomes. Am. Surg. 2005, 71, 308-314. [PubMed]

24. Thomas, H.; Agrawal, S. Systematic Review of Obesity Surgery Mortality Risk Score-Preoperative Risk Stratification in Bariatric Surgery. Obes. Surg. 2012, 22, 1135-1140. [CrossRef] [PubMed]

(C) 2019 by the authors. Licensee MDPI, Basel, Switzerland. This article is an open access article distributed under the terms and conditions of the Creative Commons Attribution (CC BY) license (http://creativecommons.org/licenses/by/4.0/). 